\title{
THE INFLUENCE OF VERMIWASH SPRAYED MULBERRY ON SOME GROWTH AND SILK PARAMETERS OF SILKWORM BOMBYX MORI L.
}

\author{
Priyadarshini P. Maddi* \& Yatheesh K. Rawgol**
}

\begin{abstract}
The influence of vermiwash on growth in ferms of weights and sizes of larvoe, feeding response in ferms of ingestibility and digestibility, silk parameters including cocoon weights, silk yarn lengths and weights, NBFL and denier of silk yarn of the mulberry silkworm Bombyx mori $L$. belonging to two races - hybrid multivoltine $K G$ race, and pure bivoltine CSR-2 have been studied. Though total ingestion and ingestibility percentage of the larvae was found to be the least in the single-feed group of KG race, denier, length and weight of silk yarn, NBFL, of the group showed higher values than the two-feed and control groups. Shortening of the larval period in KG race and influence on the cocoon shapes, sizes and consistency of cocoons of CSR 2 have also been observed.
\end{abstract}

* Professor, Dept of Zoology, Christ University.

** Lecturer, Christ College of Education, Christ University.

\# We are thankful to Dr. Radha D. Kale Emeritus Scientist, and Retd. Prof.\& H.O.D. of Zoology, G.K.V.K. University of Agriculfural Sciences, Hebbal, Bangalore for her academic inputs. 


\section{Introduction}

Vermiwash, is the body fluid extract of earthworms obtained by washing of the earthworm body surface. Generally the detritivorous epigeic earthworms feeding at or near soil surface mainly on plant litter, including dead roots and other plant debris in the organic matter-rich surface soil horizons are preferred for extraction of vermiwash.

Earthworms belong to phylum Annelida, Class Oligochaeta. Epigeic earthworms, Eudrilus eugeniae, Perionyx excavatus, Perionyx sansibaricus and Eisenia fetida live on soil surfaces feeding exclusively on partially decomposed organic matter. They are capable of surviving even in the absence of soil. These earthworms are best suited for vermicomposting as they are voracious feeders of organic matter, grow very fast, possess high reproductive potential and short life cycles. However as epigeic earthworms live on soil surfaces and are exposed to environmental hazards like predators and physical disturbances, they have to be cultured under proper protection.

Earthworms release the body fluid /coelomic fluid regularly and naturally, through the dorsal pores that are open all the time, to keep the body surface moist and facilitate respiration.. Slight stimulation through hot and cold shocks releases excess of the fluid and extraction of the same in water is popularly referred to as the 'Vermiwash'.It is colourless or milky, alkaline, containing salts, water, some proteins and different types of cells the amoebocytes, mucocytes, leukocytes and granulocytes. Production of this fluid is very significant for the animal as it kills bacteria settling on the body, removes excretory wastes, transports materials within the body, helps locomotion, luminesces the animal and acts as its hydrostatic skeleton. Vermiwash is a nutrient-rich liquid organic manure.

Vermiwash should not be mistaken with 'Vermicompost tea', the supernatant obtained on soaking vermicompost in water for two days. Nevertheless this is also a liquid organic manure, with soluble nutrients, water soluble organic substances, mucus secretions of earthworms and microorganisms.

Spraying of vermicompost tea and vermiwash on foliage has been found to produce inhibitory zones in some plants in-vitro (Kale 1997). Vermiwash, has been reported to show good callus growth when used as a component of the nutrient medium in plant tissue culture. Stimulatory effect on root induction in cuttings of two varieties of carnations, Dianthus caryophillus $L$. has also been shown. Vermiwash has been found to stimulate germination, establish cuttings and promote flowering in plants (Karuna etal., 1999). When given as a supplementary food to silkworms, vermiwash 
has been reported to improve feeding, decline incidences of diseases and increase the yield of cocoons. Vermiwash may be diluted with water or $10 \%$ cow's urine, before spraying that also acts as an effective pesticide. Vermiwash contains plant nutrients in soluble form, plant growth hormone-like substances and 'anfibiotics'.

Vermiwash contains excretory products and mucous secretions of earthworms, enzymes, along with nutrients from the soil and organic molecules.

Karuna and others (1999) have investigated the effects of vermiwash on Crinkle Red variety of Anthurium andreanum L. Lower concentrations of vermiwash were found to induce vegetative growth, like number of suckers, length and breadth of leaves and length of petiole.

The mulberry silkworm Bombyx mori L. feeds exclusively on mulberry leaves, Morus alba. It is an inhabitant of China and India introduced into many parts of the world for commercial purposes. Bombyx mori L. owes its ancestry to the wild species Bombyx mandarina. However today it is absolutely domesticated by a persistent process through time.

Silkworms belong to phylum - Arthropoda, class - Insecta, order - Lepidoptera. Bombyx mori $L$. is the common silkworm belonging to the family Bombycidae. It is a holometabolous insect. Since larval stage is the only feeding period, it grows rapidly and contributes to the development of the silk gland that secretes the silk yarn at the end of the laval stage. Thus, the larval stage is a very important period for silk-protein synthesis and cocoon formation.

Since 1991, Central Silk Research and Training Institute (CSR \& TI) has developed three basic bivoltine Central Silk Board Races CSR 2, CSR .4 and CSR 5, besides two hybrids CSR $2 \times$ CSR 4 and CSR $2 \times$ CSR 5. The cocoons are white in colour. CSR is a relatively sensitive race.

Kolar, is popularly known as the golden land of India, for its famous Kolar Gold Fields. The multivoltine Kolar Gold Race, is a product of pure Mysore race and CSR. The cocoons are yellowish in colour. It is a hardy race, tolerant to temperature fluctuations. The varieties of mulbern Morus indica specially suitable for rearing in Karnataka and Tamil Nadu are, Kanva-2,S-36,S-54, DD, MR -2. However in 1996, Victory -1 has been recommended variety for cultivation under irrigated conditions.

It is a cross of S-30 and Berc 776 developed at CSR\&TI Mysore. Its annual yield is 70 tonnes / hectare. The moisture content of young and mature leaves is $78.9 \%$ and $72.5 \%$ respectively. The protein and total sugar content is $24.6 \%$ and 
$16.98 \%$ respectively. It is reported to be moderately resistant to leaf rust and Tukra infestation and resistant to leaf spot. The added features of this variety are quick and high sprouting and rooting (>94\%), high photosynthetic rate and higher water using efficiency.

The chemical composition of the mulberry leaves differs according to variety and maturity. According to Mysore CSR\&TI report the leaves contain $65 \%-78 \%$ moisture; $19 \%$ a $25 \%$ protein; $10 \%-15 \%$ minerals; $12 \%-1.9 \%$ reducing sugars and $10 \%-15 \%$ sugars.

The silk gland is an important organ of the silk worms producing liquid silk. It is the source of the cocoon fiber. A major portion of the gland lies just below the alimentary canal. The gland has a specific shape and is broadly divided into the anterior, middle and posterior parts. The silk glands grow very fast, from the time of hatching of the larvae to the final stage of mature larvae. Growth of the silk gland involves swelling and increasing of the size of each of its cells. With the cell division having been completed during embryonic period, the number of cells in the silk glands remains constant. However, the number of cells in the silk gland is not the same in the different races of silkworms. Usually the European race has the maximum number followed by the uni- and bivoltine Japanese races, bi- and polyvoltine Chinese races which have a relatively small number of cells.

When the larvae reach the $5^{\text {th }}$ instar and grow to maturity, the silk glands grow rapidly. The growth of the silk glands reaches its peak during $5^{\text {th }}$ instar. During this period large quantity of silk is produced in the silk glands. This liquid silk ultimately comes out as the silk fibre. The production of silk is because of tremendous internal changes in the larva. After completing the secrefion of liquid silk the larva moults inside the cocoon and changes into pupa. The cocoon provides complete protection to the pupa from outside.

The cocoon fibre is composed of the proteins Fibroin and Serecin synthesized from the amino acids present in the mulberry leaves ingested by the silkworms. Fibroin forms the core of the silk fibre. It is surrounded by Serecin. These two components are different in their characteristics, and are secreted from different parts of the silk glands. Fibroin is secreted by the posterior part and Serecin is secreted by the middle part of the silk gland:

Effect of thyroxine on food utilization in the $5^{\text {th }}$ instar mulberry silkworms Bombyx mori L. has been reported (Hemavathi, and Bharathi, 2003). The increased food consumption and digestion due to thyroxine administration has been reported to positively influence cocoon yield and silk production. Magadum (1.987) reported that the dietary supplementation of iodinated compounds improved some of the 
economic characters of the silkworm, Bombyx mori L. Potassium iodide fed to the silkworm through the mulberry leaves improved the cocoon weight and silk percentage. Narasimhamoorthy ef al., (1987) reported that the leaf consumption capacity of silkworms was high in the treated group with thyroxinated leaves than the control group. The nutritional efficiency was studied during $5^{\text {th }}$ instar as $80 \%$ of food consumption during the entire laval period takes place in this instar.

Bharathi and Govindappa, (1987) reported that hormone treatment improved the general metabolism of the silkworms.

Aftab Ahmed et al., (1998) reported that the nutritional background of the larvae has a significant influence on the pupae, adult and production of silk in the commercially important insects like Bombyx mori $L$.

Morohoshi (1976) reported that food consumption has a direct influence on the weight of larva, pupa and shell. The nutritional value of the leaves plays a very important role in the improvement of the silkworms.

Muniraju et al., (1999) reported that the efficiency of conversion of mulberry leaf into silk is one of the important properties of silkworm Bombyx mori $L$.

Cui W-Z, Mu Z-M, Zhang Y-Y, Duan H-M, Zhou W-D, Lif-Q and Liu Y(1995) reported that the body weight, total amount of food ingested and digested by silkworm larvae, following treatment with juvenile hormone and ecdysone was higher than in control group. The development of the silk gland was also better.

Muni Reddy, Sheela and Nirmala (1995) have reported an increase in food intake, growth and conversion efficiency in the fitth instar larvae of Bombyx mori L. following administration of a vitamin and mineral mixture, Filibon.

\section{Materials and Methods}

The third instar larvae of Kolar Gold race (KG race) and Central Silk board 'Race (CSR2 race) are used. The former is a multivoltine hybrid of Pure Mysore race \& CSR whereas, the latter is a pure bivoltine race of Chinese origin. The silkwerms were fed with the mulberry variety Victory-1.

\section{Operational Definitions:}

1. Vermiwash: The Body fluid of earthworms extracted by giving mild shocks with lukewarm and cold water. 
2. Single feed /A group : Silkworms fed with $50 \%$ vermiwash-smeared mulberry once in the day.

3. Two feed/B group : Silkworms fed with $50 \%$ vermiwash smeared mulberry twice in the day

4. Control / C group : Silkworms fed with untreated leaves.

5. Single feed / D group : Silkworms fed with undiluted vermiwash -smeared mulberry once in the day.

\section{Parameters Studied:}

Silkworm growth parameters studied include:

1. Total ingestion per day $=$ Total leaf supplied - unfed leafleft over/day

2. Ingestibility $\%=$ Amount of ingested leaf $\times 100$ Total leat supplied

3. Total digestion per day $=$ Total leaf ingested - excreta produced / day

4. Digestibility $\%=$ Total amount of leaf digested $\times 100$ Total leaf ingested

\section{Silk parameters studied include:}

1. Denier: Total weight of the silk reeled from the cocoons multiplied by a constant and divided by product of the length of the silk reeled and the number of cocoons taken for reeling.

2. Weight of silk yarn.

3. Length of the silk yarn.

4. N.B.F.L: Non Broken Filament Length of the silk yarn while reeling, calculated by dividing the product of the length of the silk reeled and number of cocoons taken for reeling by number of reeling end. 


\section{Preparation of Vermiwash and its application on to mulberry leaves:}

Clitellated earthworms of Genus Eudrilus eugeniae were collected from the vermiculture bins. Earthworms weighing half a kilogram were placed in a dry enamel tray for 15-20 mins to clear out the cast released during handling. They were then carefully separated from their excreta (castings) and suspended in a glass beaker containing $500 \mathrm{ml}$ of luke warm distilled water $\left(37^{\circ} \mathrm{C}-40^{\circ} \mathrm{C}\right)$. The worms were mildly agitated for 3 to $5 \mathrm{mins}$, removed, and suspended into another beaker containing $500 \mathrm{ml}$ of cold distilled water at room temperature $\left(25^{\circ} \mathrm{C}-27^{\circ} \mathrm{C}\right)$, rinsed thoroughly to separate out the exudates adhering to its body wall before releasing them back to the culture bins. The contents in the two beakers were mixed and used as spray. The exudate thus collected, called the vermiwash is a syrupy, light yellow fluid. This fluid was tested in two concentrations viz.,

(a) Undiluted (100\% vermiwash)

(b) Diluted with equal quantity of distilled water ( $50 \%$ Vermiwash).

The vermiwash so prepared was stored in a dark bottle to avoid exposure to sunlight and used for experimentation. Victory-1 mulbern leaves were manually treated on both sides with undiluted and diluted vermiwash at $1 \mathrm{ml}$ per $5 \mathrm{~g}$ of leaf.

\section{Rearing of Silkworms:}

The $3^{\text {rd }}$ instar larvae just before $3^{\text {rd }}$ moult, of Bombyx mori L. belonging to two different races viz., K.G and CSR2 were collected from the Kiranageri chawki centre located near Kanakapura, Ramanagara district, and reared under a temperature of $23^{\circ} \mathrm{C}$ to $25^{\circ} \mathrm{C}$ and $70 \%$ humidity. Soon after the moult, the larvae were fed with vermiwash treated tender mulbern leaves followed by treated medium coarse and coarse leaves. As mortality was high in the undiluted vermiwash treated, first experimented race viz., CSR2 this concentration was avoided for the later reared KG race. These were fed with only diluted vermiwash- treated mulberry. However the cocoons produced by the few surviving CSR 2 larvae have been used for the analysis of silk parameters. Experiments that required the frequent handling of the silkworms were avoided due to their sensitive nature.

Three experimental groups, ' $A$ ', ' $B$ ', and ' $C$ ' of $K G$ race and an additional group ' $D$ ' in CSR2 each with 50 silkworms were maintained. The ' $A$ ' group silkworms were given one feed with the diluted vermiwash treated mulberry leaves. The ' $B$ ' group silkworms were given two alternate feeds with the similarly treated mulberry. The ' $D$ ' group silkworms were fed with undiluted vermiwash sprayed mulberry. The 
same treatment was not extended to $K G$ race, due to high mortality observed in CSR2. The ' $C$ ' group silkworms were fed with only untreated mulberry at all times. Since CSR2 race silkworms were found to be more sensitive than $K G$ race silkworms, studies requiring their frequent handling, like regular weighing of fed-unfed leaves, excreta and larvae were limited to only the KG race. Total ingestion, ingestibility percent, total digestion and digestibility percent were determined in only the KG race.

As the silkworms stopped feeding at the end of the fifth instar, they were laid on special self-made mountages, the 'Chandrikes' to spin cocoons. The time of release on to the mountages in all the groups, and variations in shapes, sizes and weights of the cocoons were noted. By the fifth day, the cocoons were deflossed and styphled to facilitate reeling later.

\section{Construction of Chandrike/Mountage:}

The size of mountage was $4^{\prime}$ by $2 \frac{1}{2}$ ' with a depth of $3^{\prime \prime}$. They were fabricated using coir rope, nails, mat, net screen, wooden frame and tags.

\section{Styphling of Cocoons:}

Styphling, is subjecting the cocoons to a very high temperature, of $120^{\circ} \mathrm{C}$ to remove moisture mixed with the air inside the cocoon faster without affecting the. inner layer of sericine. Styphling is also achieved by subjecting the pupae at $45^{\circ} \mathrm{C}$ to $55^{\circ} \mathrm{C}$ for about one hour. The process of styphling kills the pupae within the cocoon, arresting their development into adults that would naturally eclode (emerge) at the end of a normal span of 10 days cutting their way through the cocoon, damaging it. Such cocoons cannot be reeled making study of silk parameters impossible.

\section{Cocoon Cooking:}

Cocoon cooking is a major and important process in raw silk reeling. It has significant influence on silk recovery and raw silk quality. In this process water is made to permeate from outside to the inside, inside to the outside and again from outside to the inside of the cocoon shell, to soften Sercine uniformly throughout the cocoon shell. This facilitates the smooth unwinding of the cocoon filamient without causing any damage. This principle is known as "Entry -Suction" phenomenon. Cocoon cooking can be carried out in two ways viz., Pan cooking and Pressure cooking. In this experiment, the "The Two Pan Cooking Method" has been used. 


\section{Results and Discussion}

Table No.1: Ingestibility and Digestibility in the Silkworms Bombyx Mori L.: Kolar Gold Race (KG)

\begin{tabular}{|l|l|c|c|c|}
\hline SI & Parameters & \multicolumn{3}{|c|}{ Groups of KG Race } \\
\hline & & Single Feed (A) & Two Feeds (B) & Control (C) \\
\hline 1. & Total Ingestion & 303.1 & 306.74 & 323.76 \\
\hline 2. & Ingestibility \% & 73.0361 & 73.9132 & 78.0144 \\
\hline 3. & Total Digestion & 253.1 & 244.675 & 276.23 \\
\hline 4. & Digestibility \% & 83.5037 & 79.7662 & 85.3193 \\
\hline
\end{tabular}

Table No. 2: Cocoon Weights and Length of Silk Yarn of KG Race in terms of Central Tendencies

\begin{tabular}{|l|c|c|c|c|}
\hline Silkworm Groups & \multicolumn{2}{|c|}{ Cocoon Weights $(\mathrm{g})$} & \multicolumn{2}{c|}{ Length of Silkyarn (m) } \\
\hline & $\mathrm{X}$ & $\sigma$ & $X$ & $\sigma$ \\
\hline Single Feed (A) & 1.652 & 0.2073 & 185.2 & 80.0034 \\
\hline Two Feeds (B) & 1.730 & 0.1667 & 164.2 & 58.1357 \\
\hline Control (C) & 1.898 & 0.1944 & 134.2 & 51.0662 \\
\hline
\end{tabular}

Table No. 3: Cocoon Weights and Length of Silk Yarn of CSR2 in terms of Central Tendencies

\begin{tabular}{|l|c|c|c|c|}
\hline Silkworm Groups & \multicolumn{3}{|c|}{ Cocoon Weights (g) } & \multicolumn{2}{c|}{ Length of Silkyarn (m) } \\
\hline & $X$ & $\sigma$ & $X$ & $\sigma$ \\
\hline Single Feed (A) (50\% Dilution) & 1.706 & 0.1179 & 994 & 138.6578 \\
\hline Two Feeds (B) (50\% Dilution) & 1.846 & 0.2856 & 926 & 33.2365 \\
\hline Control (C) (50\% Dilution) & 1.846 & 0.3450 & 926.66 & 104.6285 \\
\hline Single Feed (D) (Undiluted) & 1.620 & 0.2921 & 909.66 & 73.6176 \\
\hline
\end{tabular}


Table No. 4: 't' test for Cocoon Weights and Length of Silk Yarn of 'A'groups of KG and CSR2

\begin{tabular}{|c|c|c|c|c|c|c|c|c|}
\hline Groups & \multicolumn{4}{|c|}{ Cocoon Weights $(g)$} & \multicolumn{4}{|c|}{ Length of Silk Yorn $(\mathrm{m})$} \\
\hline & $N$ & $x$ & $\sigma$ & 't' test & $N$ & $x$ & $\sigma$ & ' $\mathrm{t}$ ' test \\
\hline $\begin{array}{l}\text { Single Feed } \\
\text { (A) KG }\end{array}$ & 5 & 1.652 & 0.2073 & \multirow{2}{*}{$\begin{array}{c}021176 \\
\text { NS }\end{array}$} & 5 & 185.2 & 80.0034 & \multirow{2}{*}{$\begin{array}{c}102.536 \\
\text { s.at } 1.0 \% \\
\text { Df. } 6\end{array}$} \\
\hline $\begin{array}{l}\text { Single Feed } \\
\text { (A) CSR2 }\end{array}$ & 5 & 1.706 & 0.1179 & & 3 & 994 & 138.6578 & \\
\hline
\end{tabular}

Table No. 5: 't' test for Cocoon weights and Length of Silk Yarn of 'B' Groups of KG and CSR2

\begin{tabular}{|c|c|c|c|c|c|c|c|c|}
\hline Groups & \multicolumn{4}{|c|}{ Cocoon Weights (g) } & \multicolumn{4}{|c|}{ Length of Silk Yarn (m) } \\
\hline & $N$ & $x$ & $\sigma$ & 't' test. & $N$ & $\mathrm{x}$ & $\sigma$ & ' $t$ ' test \\
\hline $\begin{array}{l}\text { Two Feeds } \\
\text { (B) KG }\end{array}$ & 5 & 1.73 & 0.1667 & 0.2852 & 5 & 164.2 & 58.1357 & $\begin{array}{l}159.8371 \\
\text { s.at } 10 \%\end{array}$ \\
\hline $\begin{array}{l}\text { Two Feeds } \\
\text { (B) CSR2 }\end{array}$ & 5 & 1.846 & 0.2856 & NS & 3 & 926 & $\begin{array}{c}33.2365 \\
\vdots\end{array}$ & Df. 6 \\
\hline
\end{tabular}

Table No. 6: ' $t$ ' test for Larval Weights of 'A' and ' $B$ ' Groups of KG Race

\begin{tabular}{|l|c|c|c|c|}
\hline Groups & \multicolumn{4}{|c|}{ Laval Weights (g) } \\
\hline & $N$ & $X$ & $\sigma$ & 't' test \\
\hline Single Feed (A) & 15 & 3.1333 & 1.7701 & \multirow{2}{*}{0.48835 NS } \\
\hline Two Feeds (B) & 15 & 3.2666 & 1.8073 & \\
\hline
\end{tabular}

Table No. 7: " $\mathrm{f}$ ' Test for Larval Weights of 'A' and 'B' Groups of CSR2

\begin{tabular}{|l|c|c|c|c|}
\hline Groups & \multicolumn{4}{|c|}{ Larval Weights (g) } \\
\hline & $\mathrm{N}$ & $\mathrm{X}$ & $\sigma$ & 'f' test \\
\hline Single Feed 'A' & 15 & 3.60 & 1.8973 & \multirow{2}{*}{$0.2769 \mathrm{NS}$} \\
\hline Two Feeds 'B' & 15 & 2.4 & 1.5491 & \\
\hline
\end{tabular}


Table. No. 8: The Various Silk Parameters of ' $A$ ', $B$ ' and ' $C$ ' of KG Race

\begin{tabular}{|l|c|c|c|}
\hline Parameters (units) & \multicolumn{3}{|c|}{ Samples of KG Race } \\
\hline & Single Feed 'A' & Two Feeds 'B' & Control ' $\mathrm{C}^{\prime}$ \\
\hline Denier $(\mathrm{g} / \mathrm{m})$ & 3.335 & 3.776 & 4.10 \\
\hline Length of Silk (m) & 926 & 821 & 671 \\
\hline Weight of Silk $(\mathrm{g})$ & 1.09 & 1.07 & 0.181 \\
\hline NBFL & 71.23 & 54.733 & 15.976 \\
\hline
\end{tabular}

Table No. 9: The Various Silk Parameters of 'A','B','C' and 'D' Groups of CSR2

\begin{tabular}{|l|c|c|c|c|}
\hline Parameters (units) & \multicolumn{4}{|c|}{ Samples of CSR2 } \\
\hline & $\begin{array}{c}\text { Single Feed } \\
\text { 'A' } \\
\text { (50\% Dilution) }\end{array}$ & $\begin{array}{c}\text { Two Feeds } \\
\text { ' } \mathrm{B}^{\prime} \\
\text { (50\% Dilution) }\end{array}$ & $\begin{array}{c}\text { Control } \\
\text { ' } \mathrm{C}^{\prime} \\
(50 \% \text { Dilution) }\end{array}$ & $\begin{array}{c}\text { Single Feed } \\
\text { 'D' } \\
\text { (Undiluted) }\end{array}$ \\
\hline Denier (g/m) & 2.52 & 2.98 & 3.153 & 2.7405 \\
\hline Length of Silk (m) & 994 & 927 & 927 & 910 \\
\hline Weight of Silk (g) & 0.837 & 0.920 & 0.974 & 0.831 \\
\hline NBFL & 596 & 278 & $398 s$ & 546 \\
\hline
\end{tabular}

GRAPH 1

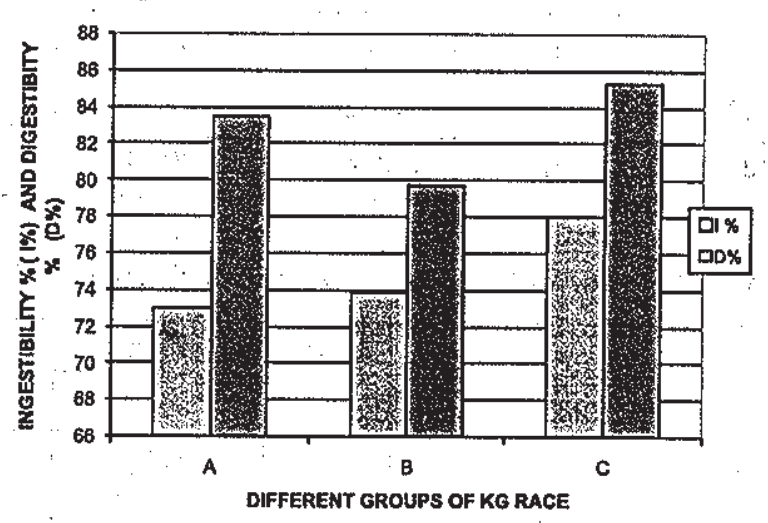


GRAPH 2

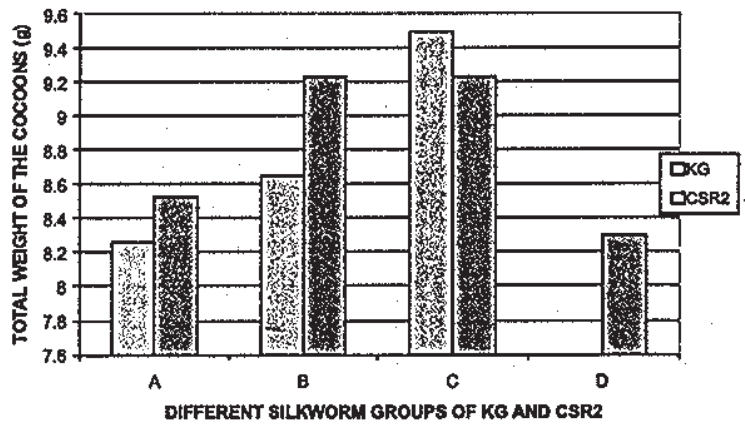

GRAPH 3
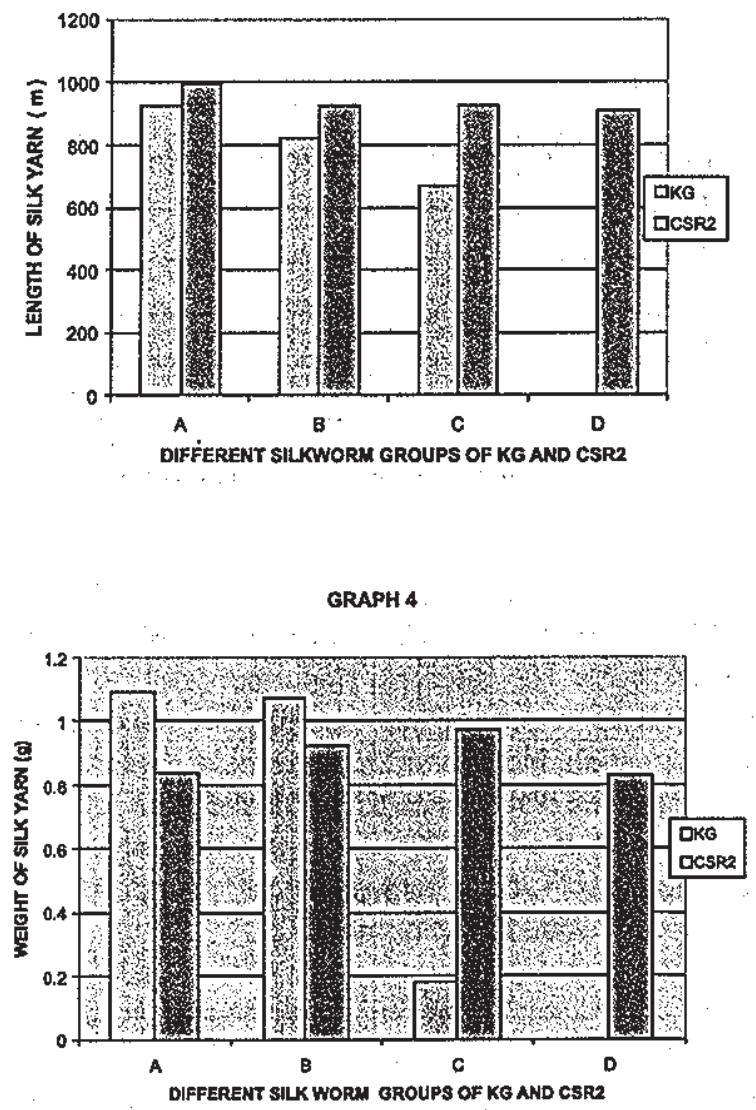


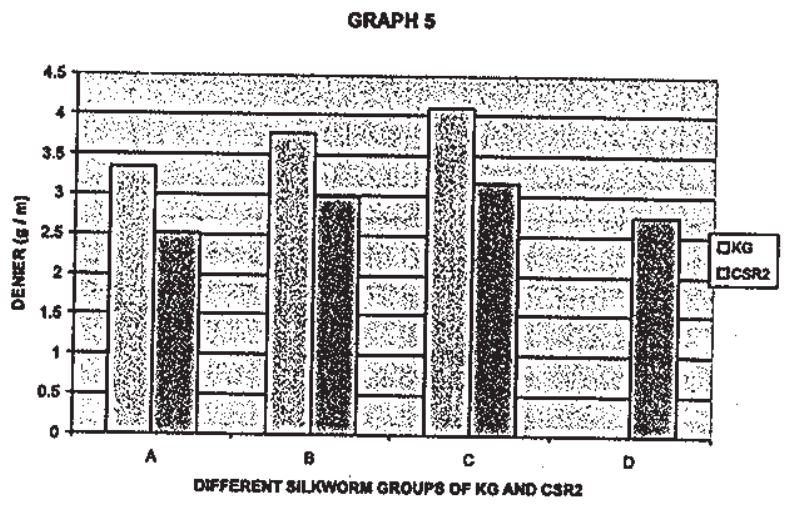

GRAPH 6

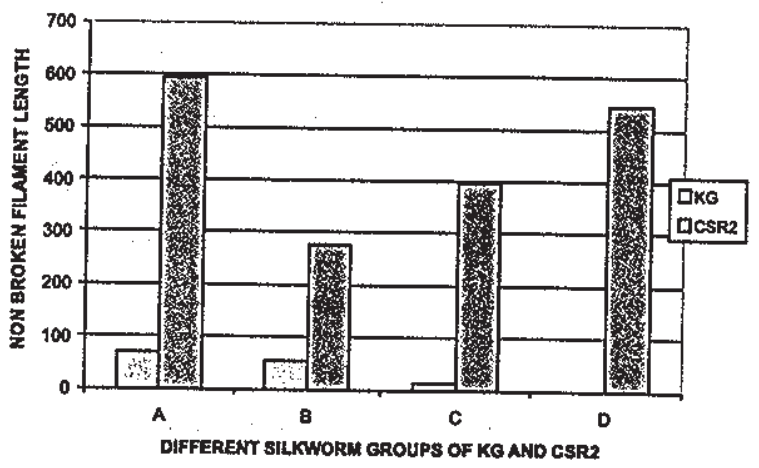

Silkworm Bombyx mori L. consumes maximum amount of mulberry in the fifth instar. Nearly 75 percent of the total leaf consumed in all the instars is ingested by the larvae in the last instar. The nutritional performance of the last instar in particular and entire larval period in general has a great influence on the health of pupae, adults and silk production. Nutritional background of the larval stage, significantly influences the state of the resulting pupa, adult and production of silk in Bombyx mori L. (Aftab Ahamed et al., 1998). The high intake of food by the fifth instar lawae is to accumulate sufficient energy resources to support its metabolism during the non-feeding pupal-adult development.

Table 1 \& Graph 1, elucidates, the feeding parameters viz., total ingestion, ingestibility percent, total digestion and digestibility percent of the silkworm Bombyx mori $L$. $K G$ race. Total ingestion and ingestibility percent was least in the $A$ group, highest 
in the $C$ group followed by that in the $B$ group. Total digestion and digestibility percent, was also found to be highest in the control, least in the ' $B$ ' group and in between in the A group. The $C$ group exhibited the highest values in both ingestibility and digestibility percent indicating that vermiwash did not enhance ingestibility or digestibility in Bombyx mori L. But between the A and B groups, total digestion and digestibility percent was more in $A$ group.

Studies concerning effect of thyroxine on food utilization by silkworm Bombyx mori $L$ (Hemavathi \& Bharati, 2003) show that there were day to day changes in the total ingestion, ingestibility percent, total digestion and digestibility percent upon feeding with thyroxine in the fifth instar lawae of Bombyx mori L. All of these feeding parameters were enhanced in thyroxine fed lanae over control through out the fifth instar, indicating increased food utilization efficiency under the influence of thyroxine. Similarly, increased leaf consumption in the thyroxine treated silkworm larvae than control was observed earlier too (Narasimhamoorthy et al., 1987).

The increase in ingestibility and digestibility may be due to increased metabolic activities resulting in enhanced larval growth and early pupation. The effect of feed addition on the silk productivity has been reported as one of the growth indices leading to the realization of two of the most important economic parameters viz., reduced lanval duration and increased shell weight. In the present study, the laval period of $K G$ race was found to be shortened by $12 \mathrm{hrs}$ in the $A$ group and $2 \mathrm{hrs}$ in the $B$ group as compared with the $C$ group.

Increased food intake in thyroxine - fed Bombyx mori L reflected directly on cocoon yield and silk production. Efficiency of conversion of mulberry into silk is one of the important properties of the silkworm Bombyx mori $L$. due to its commercial value (Muniraju et al.,1999). In the present study, the mean cocoon weight (Table. 2; Graph 2) was found to be the highest in the control group, least in the one feed group and in between, in the two feed groups of both the KG race and CSR2. Length of the silk yarn of A group was found to be longest at $185.2 \mathrm{~m}$. in KG race and $994 \mathrm{~m}$ in CSR2 followed by the length in the B group at $164.2 \mathrm{~m}$ for KG race and $926 \mathrm{~m}$ for CSR2. Control group showed a length of $134.2 \mathrm{~m}$ for $K G$ race and again $926 \mathrm{~m}$ for CSR2 (Table $2 \& 3$, Graph 3). Although the total ingestion and ingestibility percetage of ' $A$ ' group were low, they showed higher digestibility percent and silk yarn length. This is suggestive of the fact that the presence of the amino acids Glycine, Arginine and Serine in the vermiwash caused the enhanced silk production in the vermiwash treated larvae as compared to the controls. Incidentally according to a certain Chinese finding vermiwash has been reported to contain these amino acids in abundance. The crystalline fraction of fibroin amounting to $60 \%$ contains only residues of Glycine, Arginine and Serine in the ratio 3:2:1 and 
to a smaller extent Tyrosine. Glycine residues alternate with the other three amino acids almost through out the entire length of the sequence (Tazima 1973).

The significant differences in the length of silk yarn of A group over the $B$ group of $K G$ race and CSR2 indicate that while vermiwash is a definite causative factor, too much of it may not be required, and on the contrary may be inhibitory. Extra feeds with the vermiwash treated mulbern may not be pacing with the rate at which these amino acids are incorporated into silk synthesis.

The longer silk yarn of CSR2 fed with diluted vermiwash- treated mulberry as compared with group fed with undiluted vermiwash treated-mulberny suggests the greater stimulatory effect of the diluted vermiwash as compared with the concentrated one. It may be recollected that due to heavy mortality in the CSR2 larvae fed with undiluted vermiwash the same treatment was not extended to the $K G$ race larvae. However the cocoon weights of the few surviving CSR2 larvae were noted and the same cocoons were used to study the silk parameters. It is important to mention that most of the cocoons of CSR2 treated with undiluted vermiwash. were malformed with abnormal shapes, sizes and consistency.

\section{(Photograph No.1)}

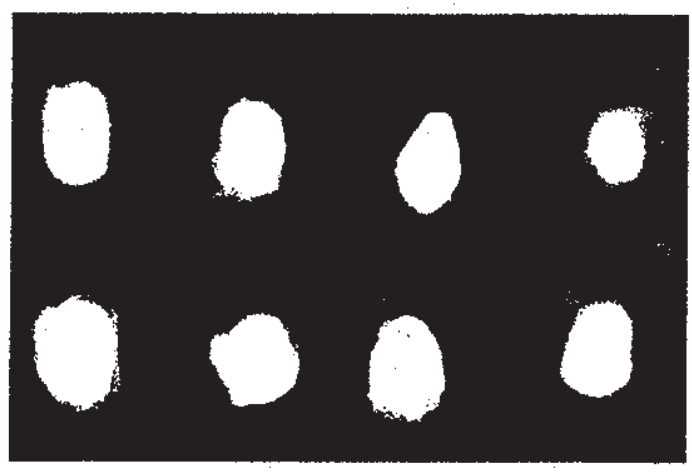

Karuna et al., reported in their study on the stimulatory effect of earthworm body fluid (vermiwash) on Crinkle red variety of Anthurium andreanum Lind. that diluting the vermiwash by adding equal quantity of water ( $50 \%$ dilution) was more effective than concentrated preparations, resulting in long lasting inflorescences of anthuriums, that bore a high premium in the international market. The diluted vermiwash has been reported to induce vegetative growths like number of suckers, length of the petiole, and early flowering. 
While incidences of the effect of vermiwash on plant growth are substantial, its effect on animal growth and commercial growth parameters like that on the silk parameters of Bombyx mori $L$, are not there. Incidentally the present study undertaken, related to the effect of vermiwash on growth of silk worms Bombyx mori $L$. and its influence on silk parameters is very relevant and path breaking.

Vermiwash is the coelomic fluid of earthworms, poured out on minimal disturbance through their dorsal pores. It contains phosphates, sulphates and chlorides of potassium, sodium, magnesium, sulfur, iron certain organic acids, ammonia and urea. All these being in the soluble form, can diffuse through the plant systems through the stomatal openings. Dilution of the vermiwash improves the absorbance efficiency of the leaves.

In the present study when CSR2 larvae were fed with mulberry leaves sprayed with both undiluted and diluted vermiwash, the larvae responded better to diluted vermiwash sprayed mulberry leaves. While the cocoon weights of the control and $B$ group were similar, they were found to be slightly higher than those of the A group. When the length of the silk yarn was considered, that of the A group was the highest at $994 \mathrm{~m}$, with $926 \mathrm{~m}$ and $926.66 \mathrm{~m}$ in the $B$ and $C$ groups respectively and the least ie., $909.66 \mathrm{~m}$ in the $D$ group. Table nos. $4 \& 5$ portray the racial differences in response to treatment between the $A$ groups and $B$ groups of $K G$ and CSR2 (Graph nos 2-6).

The larval weights of all the groups of $K G$ race did not show any significant change to feeding with undiluted vermiwash treated mulberry (Table 6).

The lesser mean weight of the larvae of the B group of CSR 2 suggests the probable inhibitory effect of the vermiwash on the growth of the silkworm lavae on being fed with the treated mulberry at frequent intervals (Table 7).

Though, the larval and cocoon weights of the $A$ group of $K G$ race silkworms were lesser than the $B$ and $C$ groups, its length of silk yarn was the longest.

The influence of vermiwash on the silk parameters have been found to be interesting and significant. A comparison of the A, B and C groups revealed that Denier in the A group was the least, length of the silk yarn and Non Broken Filament Lengths of the A group were the highest, in both the KG race and CSR2 (Tables nos. 8 \&9; Graph nos 4-6)

la E.L-Karaksy M. Idriss (1990) reported that ascorbic acid treated mulbern enhanced silk yield of the mulberry silkworm Bombyx mori L. Ascorbic acid at $0.25 \%, 0.5 \%, 1 \%$ and $2 \%$ increased the weights of both larvae and pupae, producing heavier and fresh cocoons. 
Enhanced cocoon characters, including silk filament length per cocoon, denier per filament, and reelability of cocoons has been reported on topical application of the hormone Estradiol- 17 beta at I micro gram/ $\mathrm{g}$ to the first and second day larvae of the fifth instar (Keshan, B and Ray A.K. 1999).

Increased silk filament length, Non Broken Filament Length and reelability percentage has been reported in response to feeding with mulberry treated with Juvenile hormone (JH) analogues, methoprene, a molting hormone analogue, phytoecdysone ( $\mathrm{MH}$ - III) and combinations of these in hybrid bivoltine races of the Chinese (Jufang) and Japanese (Chexin) origin. However, as methoprene concentrations increased, corresponding decreases in the rate of fibroin synthesis have been recorded suggesting a negative influence on protein synthesis. Studies of Sarangi (1988) also confirm the decrease in fibroin rate as the concentration of the hormone applied increased.

Fibroin is synthesized in the granular Endoplasmic reticulum of cells from the posterior portion of the silk gland, transported to the Golgi complex of these cells and condensed to globules of fibroin. Liquid fibroin released into the lumen of the gland is carried to the spinnerets, the labial glands that secrete the silk, during cocoon formation (Akai et al., 1973). High levels of the JH analogue inhibit the intracellulartransport of fibroin (Akai \& Kiguchi, 1980). As such in spite of increased fibroin synthesis silk secretion is affected above a certain concentration of the hormone affecting cocoon weight. In the present study, the decrease in the length of the silk yarn with increase in the number of feeds ( $B$ group) with vermiwash smeared mulberry leaf in Bombyx mori L. KG race and CSR2 is probably due to a similar mechanism obstructing the intracellular transport of fibroin .

The length of the silk yarn in both the races was maximum in the A group, with the values of $B$ and $C$ groups staggering behind. However the higher cocoon weights in the $B$ and $C$ groups as compared with $A$ group indicates that the excess weight is probably due to the pupa inside and not related to the cocoon shell weight.

\section{References}

1. Aftab Ahamed, C.A., Chandrakala, M.V, Shivakumar, C and Roghuraman R. (1998) Food and water utilization patterns under restricted feeding durations in pure Mysore race of Bombyx mori L. J. Exp. Zool. 1(1) : 29-34

2. Akai, H. Kiguchi, K., Mori K. (1973). Influence of JH on the growth and metamorphosis of Bombyx mori L. larvae. Bombyx mori L . 25 : 287-305.

3. Akai and Kiguchi K.(1980). Ultrastructural change of the posterior silk gland Cells from the allatectomised fourth instar Jarvae of Bombyx mori L. Bulletin of the sericultural experimentation of Japan. $28: 1-14$. 
4. Bharati, D Kumar and Govindapa, S (1987). Effect of prostaglandin F2 on the growth pattem of the silkworm larvae of Bombyx mori L. XV International Sericultural Congress, Sericologia, 27a : 355-358

5. Central Silk Board. (2003) Bangalore Sericulture Business. A user's guide : Farm and Industry Sectors.

6. Chemical composition and quality of Mulberny leaves Victoria-1( 1976). Text Book of Tropical Sericulture. GKVK Pub : 154-165

7. Hemawathi and Bharati (2003) Google.com.

8. la E.L, Karaksy M Idriss (1990) .Google.com

9. Kale, R.D, Bano, K, Srinivas, M.N and Bhagyaraj, D.J( 1997). South India Horticulture. $35: 433.457$

10. Kale, R.D and Bano, K (1994) Mitt.Hamb. Zool Mus.Inst.Band Hamburg. ISSN 0072. $9612 ., 89: 139-148$.

11. Karuna, K, Patil, C.R, Narayana Swamy P and Kale, R.D (1999), lbid: 253-257.

12. Keshan 8, Ray A.K. (1998) Action of Estradiol-17 beta on the synthetic activity of the silkgland in Bombyx mori L. J.insect.Physiol.

13. Magadum, S.B (1987) Studies on the effect of chemicals and hormones on the gonads and life cycle of silkworm Bombyx mori L. Ph .D thesis, Univ. of Karnataka, Dhanwar, India.

14. Morohoshi, S (1978) . Developmental Physiology of silkworm. In the silkworm- An important laboratory tool, Y Tazima Ed. Tokyo Univ.Press.

15. Muniraju, E, Shekharappo, B.M and Raghuraman R (1999). Effect of temperature on leaf silk conversion in Bombyx mori L. Sericologia, 39 (2) : 225-231.

16. Narasimhamurthy, C.V, Hurkadi,H.K and Thyagaraj, B.S (1987) Effect of Thyroxine on the growth and development of the silkworm Bombyx mori L.J. Seric. Sci. Jpn. $56: 351.352$

17. Tazima, Y. (1978). The silkworm - An important laboratory tool. Kodamishu Publishing Co.

18. Sarangi, S.K (1988) Effect of JH analogue on the silk gland of the silkworm Bombyx mori L. Sericologia, 28 : 553-557. 